\title{
Attitudes of mental health workers to treatment in their own workplaces
}

\author{
John Stephens, Mark Prunty and Wojciech Falkowski
}

\begin{abstract}
Recent questions have been rolsed regarding the development of policles by truts for the treciment of thelr locelly realdent steff outside the hospltats in which they work. A questionncire was developed to ellift viows of mental health care workers on this bsews. Ovenwholming agreement was found anong a wide variety of stafl groups on the need for provistion of treatment options outside the local service. Considerable thought and planning are needed in the development of formal operational policies to ensure such a senvice is provided by all hospliats/Trusts.
\end{abstract}

A recent statement by the President of the Royal College of Psychiatrists (1994) highlighted the rising concern surrounding the treatment of National Health Service (NHS) hospital workers within the new internal market. There is as yet no clear policy for provision of treatment for hospital staff who reside within the area served by the hospital where they work. Financial considerations may encourage Trusts to restrict the access of hospital workers to treatment outside their own Trusts. Brown \& Russell (1994) reported on a survey of 12 Community Mental Health Unit General Managers and concluded that none of the Trusts had any clear policy on this issue. To date, mental health workers whose treatment would be affected have not been asked for their opinions. We set out to identify the attitudes of mental health care workers.

\section{The study}

One hundred and seventy-six questionnaires were distributed to mental health workers within community teams, hospital-based staff, and clerical and social workers serving an inner city South London community. To ensure maximum return, the questionnaires were distributed and collected by hand. The questionnaire contents are set out in Table 1 .

\section{Findings}

One hundred and seventy-two responses were collected (97.7\%). Sixty-three per cent of the respondents were female; $4 \%$ did not specify gender.

\section{Occupation}

The occupational profile was as follows: clerical/ secretarial staff $12.8 \%$; community psychiatric nurses 16.3\%; occupational therapists $11.6 \%$; psychiatrists $16.3 \%$; psychologists $13.4 \%$; social workers 9.3\%; ward-based nurses $15.1 \%$; other (e.g. intenstve outreach worker, day hospital nurse, out-patient department nurse, or student nurse) $5.8 \%$.

The number of years working in a profession ranged from three months to 48 years (mean: 8 years).

\section{Treatment options}

Responses concerning the treatment options listed in Table 1 were as follows $(n=172)$ :

(a) Physical treatment: 'definitely yes' 149 (86.6\%); 'probably yes' (11\%); 'probably no' 4 (2.3\%).

(b) Psychotherapy/counselling: 'definitely yes' 169 (98.3\%); 'probably yes' 3 (1.7\%).

(c) Psychiatric treatment: 'definitely yes' 171 (99.4\%); 'probably yes' 1 (0.6\%).

\section{Additional comments}

The majority of additional comments made reinforced the view that special arrangements should be made available for treatment outside the local Trust. Questions were raised about possible scenarios that might arise, such as being sectioned by colleagues. In particular, a case was reported of a respondent who had been treated locally as an in-patient, and whose private files had been made available to work colleagues. The problem of obtaining treatment elsewhere was 
Table 1. Questionnaire

Gender (male/female):

Occupation:

Number of years working in above profession:

Physical illiness: if a member of the hospltal staff wishes to be treated for physical illness outside the Trust in which he/ she is working (even though such treatment is available within his/her Trust), should such provision be available? (please tick below)

yes, definitely

yes, probably $\square$

probably not

definitely not

Counselling/psychotherapy: If a member of the hospital staff requires counselling or psychotherapy, should provision be avallable for this outside the Trust in which he/she is working? (please tick below)

yes, definitely $\square$

yes, probably $\square$

probably not $\square$

definitely not $\square$

Psychiatric treatment: if a member of the hosplital staff requires psychiatric treatment should provision be avallable for this outside the Trust in which he/she is working? (please tick below)

yes, definitely

yes, probably $\square$

probably not $\square$

definitely not $\square$

Additional comments:

also raised. Those reporting success had generally achieved this through informal means with the help of family, friends or colleagues. The need for arrangements in neighbouring districts to be widely publicised was emphasised.

\section{Comment}

Mental health care workers wish to maintain the traditional option for treatment outside their place of work in cases of psychiatric treatment; and a similar view exists regarding access to psychotherapy and counselling. As regards physical illness the results were only slightly less overwhelming; but the additional comments suggested a greater concern about particular types of illness, and gynaecological disorders in particular.

The unanimous responses indicate the importance of this issue to NHS staff. Particularly at the present time of structural and contractual changes in the Health Service, it is clear that the issues raised need to be addressed formally and in some detail by Trusts. Trusts have a clear duty to ensure confidentiality for their patients.
This is substantially compromised for their staff if they have no easily available choice other than treatment at their own place of work.

Ethical issues are not the only important aspect of provision of treatment by the Trusts. It appears that so far little thought has been given to the medico-legal complexity which may arise. Clearly the independence of a former or present work colleague in being the Reglonal Medical Officer (RMO) for a detained member of staff or in carrying out a Mental Health Act assessment might be challenged. The role of the managers in the Appeal procedure would also be compromised as might the evidence of the professional witness, often a ward occupational therapist, at an Appeal. Some disorders are unlikely to lead to detention under the Mental Health Act. Both the general practitioner (GP) and the patient may feel that the benefits of local treatment outweigh any disadvantages. Even a cursory consideration of the potential medico-legal implications must give cause for concern over the lack of detailed consideration of policy given so far to this issue.

Issues of ease of access to services, maintenance of confidentiality in the process, extent of therapies included in any special procedures, and the 
possible appropriate extension of these to some family members need to be considered. Other areas such as procedures for Mental Health Act Sections are important, as is the longer-term provision for follow-up care.

It is clear that considerable thought and planning are essential if an appropriate service for mental health care workers is to be maintained. In the past, special arrangements for staff have been locally arranged (e.g. reciprocal arrangements with nearby hospitals). This is a very important issue for staff and should be reflected at the level of the 'commissioning process'. All Trusts should be expected to set up suitable local arrangements for the urgent provision of in-patient psychiatric treatment for staff outside their district. This needs to be clearly documented in an operational policy and widely distributed and made known to all staff. In addition, a suitable procedure should exist to facilitate the provision of less urgent psychiatric and psychological therapy outside of the Trust.

The specific needs of the patient-staff member should finally determine the provision of suitable care. For this reason we would suggest that the 'catchment area' teams maintain 'responsibility' for the patient unless or until other suitable arrangements have been made (with due regard to confidentiality in the process). This may, in practice, be important in assisting the GP to consider with the patient the optimal care plan. Access to the local psychiatric team's knowledgebase regarding voluntary and other local services, as well as local specialist services, might assist in finding a more suitable referral option. In time the team may be called upon to assist in enabling, or providing, optimal follow-up care. For some staff, the Trust-negotiated referral option may be clearly inappropriate and in these cases the GP or psychiatrist may request for an alternative extra-contractual referral. This should be an avallable and understood option in such cases.

In conclusion the proper provision of care and confidentiality which the Health Service has a duty to provide, applies equally to members of staff within a Trust. For this reason, commissioners of services and purchasers and providers of care need to have developed suitable procedures for the provision of in-patient care outside of the Trust, and to have developed proper procedures for the provision of other psychiatric and psychological care as appropriate. It is vital, however, that local mental health teams see themselves as assisting the GP and patient in finding the most suitable provision of care for their particular needs. The appropriate procedures and persons responsible for them within the Trust need to be widely discussed and understood.

\section{References}

BROWN, R. \& RUSSEU, H. (1994) The provision of psychiatric treatment for mental health colleagues in the new market economy. Psychiatric Bullettin, 18, 22-23.

President of the Royal College of PSYCHIATRISTS (1994) Comment. Psychiatric Bulletin, 18, 23-24.

John Stephens, Registrar in Psychiatry, Springfield University Hospital, 61 Glenburnie Road, London SW17 7DA; "Mark Prunty, Senior Registrar. St George's Hospital and Medical School, Department of Adult Psychiatry. Clare House, St George's Hospital, Blackshaw Road, London SW17 OQT, and Wojciech Falkowskd, Consultant Psychiatrist and Hon. Senior Lecturer, Springfield University Hospital

"Correspondence: Dr Mark Prunty, 82 Compton Road, Hayes, Middlesex UB3 2 AZ. 